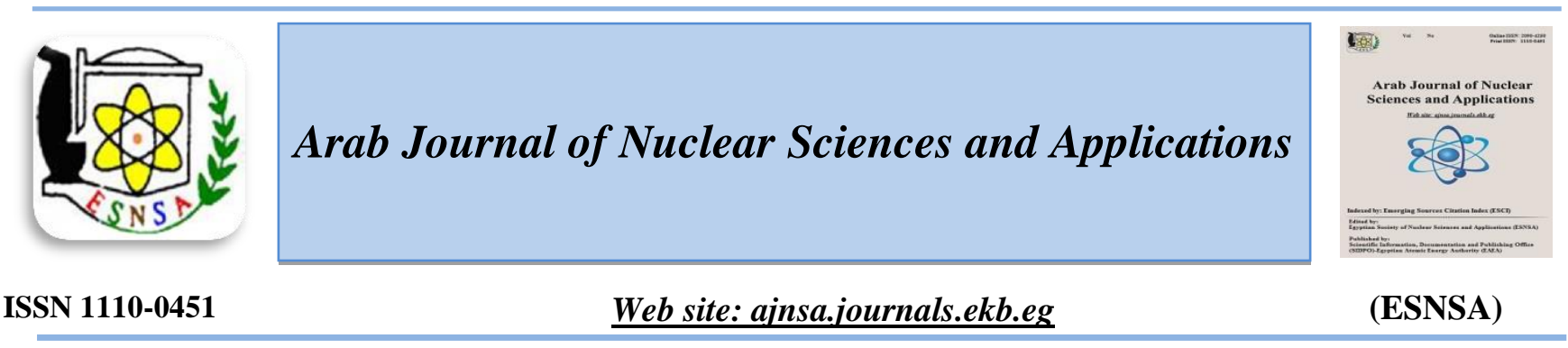

\title{
Plasma Current Sheath Dynamics and Energy Dissipation in a Low-Energy Plasma Focus Device
}

\author{
A. A. Lashin', T. M. Allam ${ }^{1}$, H. A. El-sayed ${ }^{1}$, K. M. Ahmed ${ }^{1,}$, S. A. Ward ${ }^{2}$, M. A. Abouelatta ${ }^{2}$ and H. \\ M. Soliman ${ }^{1}$ \\ Plasma and Nuclear Fusion Department, Nuclear Research Center, Atomic Energy Authority, Egypt \\ Electrical Engineering Department, Faculty of Engineering at Shoubra, Benha University, Egypt
}

Received $19^{\text {th }}$ Aug. 2019 The present study reports the measurements of plasma current sheath (PCS) dynamics, the energy Accepted 22 ${ }^{\text {th }}$ Dec. 2019 dissipation processes, and the plasma focus (PF) electrical characteristics, particularly during the axial phase discharge in a Mather-type PF device (EAEA-PF1) energized with a $30 \mu F$ capacitor bank charged with 8,10 and $12 \mathrm{kV}$. All these investigations carried out under discharge conditions where the optimal PF action is achieved. At each charging voltage $\left(V_{c h}\right), 8 \mathrm{kV}, 10 \mathrm{kV}$ and $12 \mathrm{kV}$, the optimal PF action is studied at different argon gas pressures $(P)$ ranging from 0.4 to 1.2 Torr. The results show that the best $P F$ is formed at $V_{c h}=8 \mathrm{kV}$ and $P=0.6$ Torr, $V_{c h}=10 \mathrm{kV}$ and $P=0.8$ Torr, and $V_{\text {ch }}=12 \mathrm{kV}$ and $P=0.8$ Torr. The implosion velocity $\left(V_{z}\right)$ results of $P C S$ show that the maximum value of $V_{z}(4.48 \mathrm{~cm} / \mu \mathrm{s})$ occurs at the end of the axial phase (i.e., at the coaxial electrode muzzle), which is detected at $V_{\text {ch }}=12 \mathrm{kV}$ and $\mathbf{P}=0.8$ Torr. Moreover, a less inefficient snowplow action is observed under these discharge conditions. The energy dissipation process data indicate that at $V_{c h}=12 \mathrm{kV}$ and $P=0.8$ Torr, the ratio between the total energy dissipation and the input energy has a maximum value of $\cong 90 \%$, and the minimum residual energy left on the condenser bank $(175.39 \mathrm{~J})$ is also achieved under these discharge conditions.

Keywords: Plasma focus, plasma current sheath, focus action, energy dissipation

\section{Introduction}

Plasma focus (PF) devices were independently developed in the early 1960 s in both the former Soviet Union [1] and the USA [2]. In these facilities, high-temperature (1-2 keV), highdensity $10^{25}-10^{26} \mathrm{~m}^{-3}$, short-lived plasma was produced. The original device was a coaxial accelerator [3], that induced a magnetic field behind an ionized layer (called a current sheath (CS)). The magnetic field pushes the CS with a Lorentz force $\left(\mathrm{F}_{\mathrm{z}}=\mathrm{J}_{\mathrm{r}} \times \mathrm{B}_{\theta}\right)$ to reach a high axial velocity on the order of $10^{7} \mathrm{~cm} / \mathrm{s}$ [4]. PF devices have been constructed in a variety of sizes in correlation with the energy stored in the pulsed electrical generator, ranging from kilojoules [5-6] to megajoules [5].

The external inductance $\left(\mathrm{L}_{\mathrm{e}}\right)$ and resistance $\left(\mathrm{R}_{\mathrm{e}}\right)$ of the PF capacitor bank are considered important parameters in determining the behaviour of the current waveform supplied to the machine $[6,7]$. The most reliable method for determining the PF circuit parameters $\left(\mathrm{L}_{\mathrm{e}}\right.$ and $\left.\mathrm{R}_{\mathrm{e}}\right)$ is the short-circuit test. Analysis of two or three cycles of the current waveform yields approximate values of $L_{e}$ and $R_{e}$,

Corresponding author: kamal hagag@yahoo.com

DOI: 10.21608/ajnsa.2019.16003.1256

(C) Scientific Information, Documentation and Publishing Office (SIDPO)-EAEA 
provided that the bank capacitance $\left(\mathrm{C}_{0}\right)$ is known $[6,8]$. The electrical parameters of the PF, such as the plasma inductance and plasma resistance, are time-varying parameters that are affected by the variation in the charging voltage and the working gas pressure [11-16]. Experimental investigations show that the focus action in a PF device is affected by a number of factors, including the inner electrode (IE) length and material [17-18], the insulator sleeve length and material [19-20], the polarity of the IE [9] and the pressure of the filling gas [22-23].

The discharge current and tube discharge voltage are the basic measurements of the PF. Based on these signals and some simple calculations, a great deal of information can be extracted for analysing the dynamics and performance of the PF device [10]. Different studies have been performed to determine the plasma current sheath (PCS) dynamics during the axial acceleration phase of discharge and the CS profile in the Sahand Filippov-type PF with neon at different pressures and various working voltages $(10-18 \mathrm{kV})$ [11].

During the axial phase, the motion of the CS is characterized by a roughly constant axial velocity (approximately $10^{7} \mathrm{~cm} / \mathrm{s}$ ). After this phase, the plasma sheath rapidly converges to the axis, and the stored magnetic energy converts to plasma energy in the focus [26-27].

The energy stored (E) on a condenser bank of $\mathrm{C}_{0}$ capacitance that is charged to the desired voltage $(\mathrm{V})$ is given by $1 / 2 \mathrm{C}_{0} \mathrm{~V}^{2}$. The energy is dissipated into PF discharge in three ways: magnetic energy, mechanical energy and heat dissipation $[11,28$ 29].

The main purpose of this study is to investigate the $\mathrm{PF}$ action, electrical parameters of PF discharge and circuit, the dynamical plasma distribution during the axial phase and the energy dissipation in the PF discharge.

\section{Experimental Setup}

The experiments were conducted on a low-energy $(0.96-2.2 \mathrm{~kJ})$ Mather-type PF device. This device was driven by a $3 \times 10 \mu \mathrm{F}$ condenser bank charged to $12 \mathrm{kV}$. The stored energy on the capacitor bank was transferred to the PF electrode system through an atmospheric spark gap switch.

The electrode configuration of our device was a coaxial electrode system consisting of a squirrelcage-type outer electrode (cathode) and a cylindrical inner electrode IE (anode) separated by an insulator at the coaxial electrode breech where breakdown occurs. The electrode system consisted of a central cylindrical anode with a diameter of $4.5 \mathrm{~cm}$ that had a screw at its bottom (the screw allows the anode length to be changed), which was encircled by eight cathode rods that were $18 \mathrm{~cm}$ in length and $1 \mathrm{~cm}$ in diameter, each of which was placed symmetrically around the anode. This configuration formed a $9 \mathrm{~cm}$ diameter cathode. The coaxial electrodes were made of brass and were screwed to a brass circular plate at the breech. The two electrodes were separated by a 2.1 $\mathrm{cm}$ long Pyrex glass cylindrical insulator fixed around the bottom of the anode. The anode was connected to the high-voltage terminal of an energy storage capacitor through a fast highcurrent switch, and the cathode was grounded. The entire coaxial electrode system was placed inside a stainless-steel vacuum chamber with a length of 35 $\mathrm{cm}$ and a diameter of $41.7 \mathrm{~cm}$. Different ports existed in the chamber for gas inlets, vacuum systems, vacuum gauges and diagnostics. The chamber was evacuated to a proper vacuum with a rotary vacuum pump and then filled with the working gas (argon gas) at pressures ranging from 0.4 to 1.2 Torr. The device was energized by a capacitor bank consisting of three low-inductance $(10 \mu \mathrm{F})$ capacitors. The capacitors were connected in parallel with two brass plates for positive and negative poles, which in turn were connected to an air gap switch through 24 coaxial cables. A triggering system consisting of a spark gap switch and a high-current pulse triggering circuit was used to charge and discharge the capacitor bank. A schematic of the PF device and its electrical circuit is shown in figure 1. The discharge current and voltage were measured using a Rogowski coil and resistive potential divider, respectively.

\section{Results and discussion}

The experimental work is divided into three parts: the first part addresses the characteristics of PF action, the second part addresses the electrical parameters of PF discharge and sheath implosion velocity, and the third part addresses the study of energy dissipation during the axial phase of $\mathrm{PF}$ discharge. Experimental results are taken as an average of three to five shots for each discharge condition.

\section{Characteristics of PF action}

Arab J. Nucl. Sci. \& Applic. Vol. 53, No. 1 (2020) 
The optimal PF formation conditions are separately investigated from the measurements of area and the full width at half maximum (FWHM) of the voltage spikes. All these investigations are carried out at argon gas pressures (P) within the range of 0.4 to 1.2 Torr and various charging voltages $\left(\mathrm{V}_{\mathrm{ch}}\right)$ from 8 to $12 \mathrm{kV}$. Some of the discharge current and voltage signals are shown in figure $2(a, b, c)$ for different conditions of $V_{c h}$ and P.This figure shows that for $\mathrm{V}_{\mathrm{ch}}=12 \mathrm{kV}$, the voltage probe signal exhibits multiple peaks that may contribute to multiple compression phenomena in the PF column. These spikes are generated because the PF column exhibits instability growth. In general, the multiple compressions are dependent on $\mathrm{V}_{\mathrm{ch}}$ and $\mathrm{P}$.

Figure $3(\mathrm{a}, \mathrm{b}, \mathrm{c})$ describes the variation in the voltage spike area $\left(\mathrm{V}_{\mathrm{S} . \mathrm{A}}\right)$ or the intensity of $\mathrm{PF}$ action with respect to different argon gas pressures and charging voltages. Figure $4(a, b, c)$ shows the variation in the FWHM of voltage spike time ( $\left.t_{\mathrm{FWHM}}\right)$ with respect to different gas pressures for the same charging voltages mentioned above. The maximum values of $\mathrm{V}_{\mathrm{SA}}$ and $\mathrm{t}_{\mathrm{FWHM}}$ at different gas pressures and charging voltages are listed separately in table 1 .

All the above results verified that the optimum PF formation at each charging voltage is detected at 8 $\mathrm{kV}-0.6$ Torr, $10 \mathrm{kV}-0.8$ Torr and $12 \mathrm{kV}-0.8$ Torr.

\section{Electrical circuit characteristics of PF discharge and sheath implosion velocity}

\section{Electrical circuit characteristics of PF discharge}

At the same discharge conditions mentioned above, the electrical circuit characteristics of PF discharge, such as total inductance $\left(L_{t}\right)$, total resistance $\left(R_{t}\right)$ and total load impedance, are measured as a function of discharge time $(t)$ from the following equation [31]:

$$
\mathrm{I}(t)=I_{0}(\sin \omega t) \cdot \mathrm{e}^{-\frac{R_{t} t}{2 L_{t}}}
$$

where $I(t)$ is the discharge current at time $t, I_{0}$ is the maximum discharge current and $\omega$ is the angular frequency.

$$
\omega=\frac{2 \pi}{\tau}=\sqrt{\frac{1}{L_{t} C_{0}}-\frac{R t^{2}}{4 L_{t}^{2}}}
$$

From equation (1), $\frac{R_{t}}{L_{t}}$ can be detected for different charging voltages and different discharge times, and consequently, from equation (2), $R_{t}$ and $L_{t}$ can be separately estimated at each argon gas pressure under consideration.

Figures 5 and 6 show the relation between $R_{t}$ and $P$ and that between $L_{t}$ and $P$, respectively. These figures show that the minimum and maximum values of $R_{t}$ and $L_{t}$ are detected at $V_{c h}=12 \mathrm{kV}$ for all gas pressure values under consideration. The values of $R_{t}$ and $L_{t}$ at the optimum discharge conditions of $\mathrm{PF}$ formation for each charging voltage of $8 \mathrm{kV}, 10 \mathrm{kV}$ and $12 \mathrm{kV}$ are listed in table 2 .

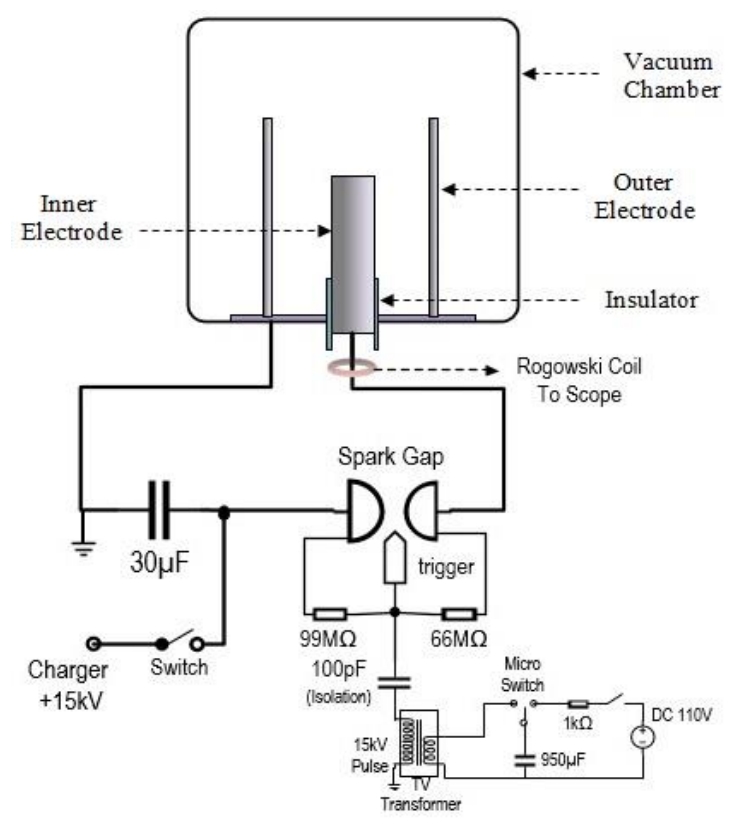

Figure 1: Schematic of the PF device and its electrical circuit [30]. 


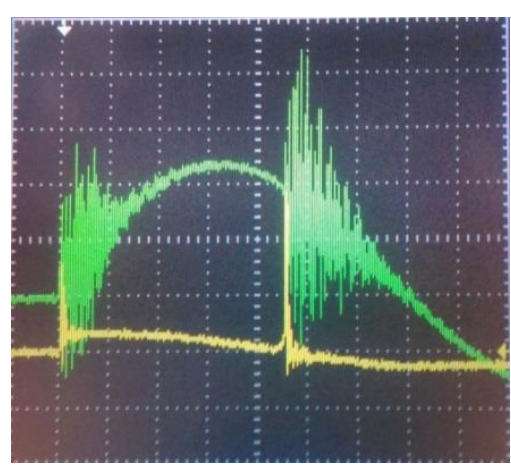

(a) $8 \mathrm{kV}-0.6$ Torr

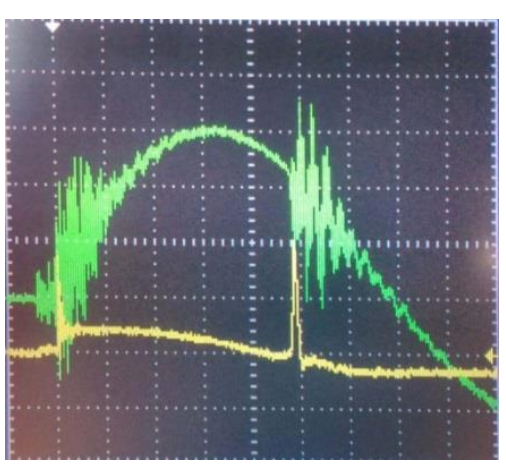

(b) $10 \mathrm{kV}-0.8$ Torr

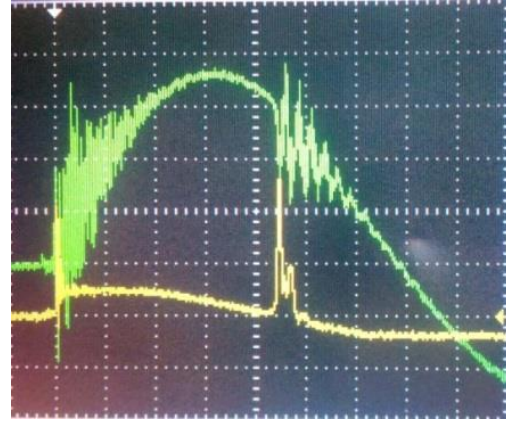

(c) $12 \mathrm{kV}-0.8$ Torr

Figure 2: Signals of discharge current and voltage ( $1 \mu \mathrm{s} / \mathrm{div}$ on $\mathrm{X}$-axis).

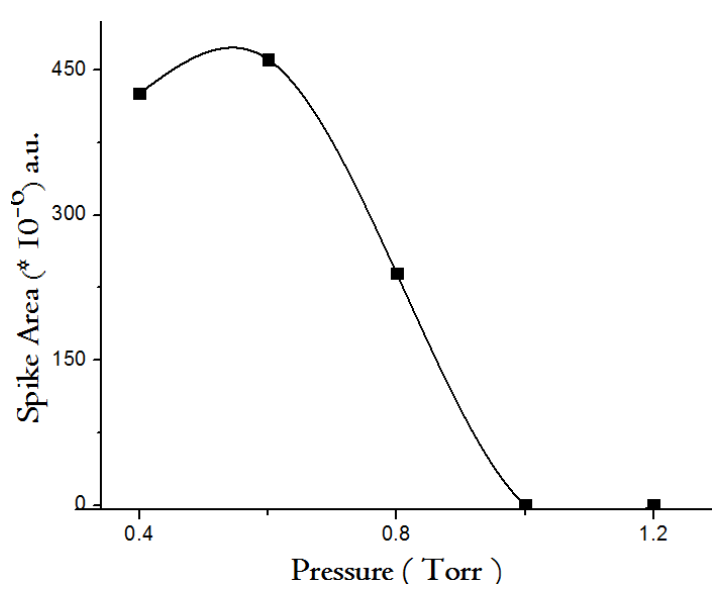

(a) $8 \mathrm{kV}$

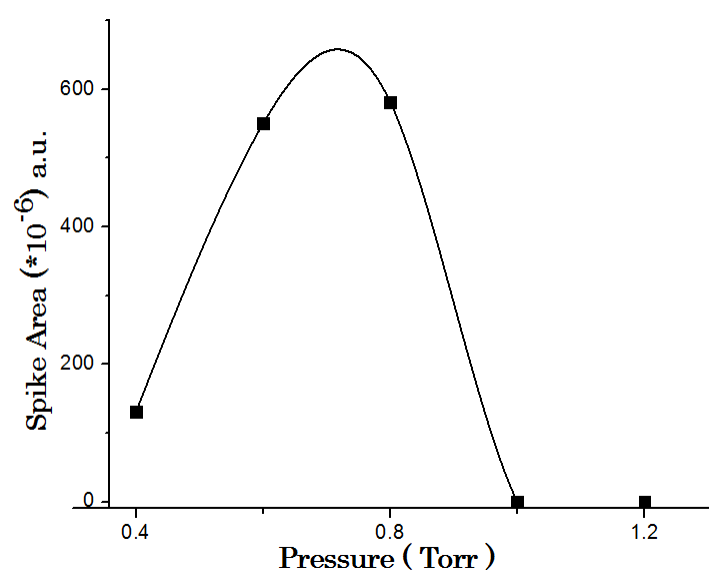

(b) $10 \mathrm{kV}$

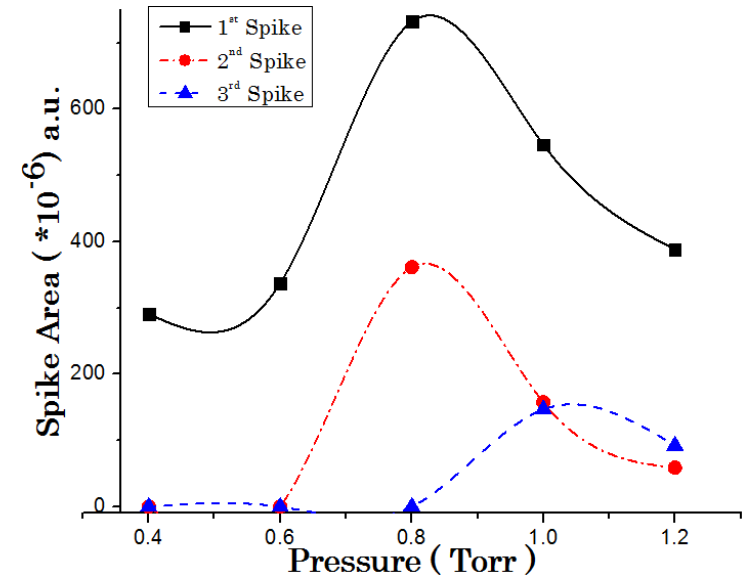

(c) $12 \mathrm{kV}$

figure 3: voltage spike area vs. gas pressure at (a) 8, (b) 10, and (c) $12 \mathrm{kv}$

Table 1: Data of optimum PF formation for each charging voltage and gas pressure under consideration

\begin{tabular}{|c|c|c|c|}
\hline & $8 \mathrm{kV}-0.6$ Torr & $10 \mathrm{kV}-0.8$ Torr & $12 \mathrm{kV}-0.8$ Torr \\
\hline$\left(\mathbf{V}_{\mathbf{S . A}}\right)_{\text {max. }}$ & $461.13 \times 10^{-6}$ a.u. & $581.2 \times 10^{-6}$ a.u. & $1^{\text {st }}$ spike: $731.85 \times 10^{-6}$ a.u. \\
\cline { 3 - 4 } & & & $2^{\text {nd }}$ spike: $361.4 \times 10^{-6}$ a.u. \\
\cline { 3 - 4 } & & & $3^{\text {rd }}$ spike: $147 \times 10^{-6}$ a.u. $($ at $\mathrm{P}=1$ Torr $)$ \\
\hline$\left(\mathbf{t}_{\mathbf{F W H M}}\right)_{\max .}$ & $34.2 \mathrm{~ns}$ & $1^{\text {st }}$ spike: $54.73 \mathrm{~ns}$ \\
\cline { 3 - 4 } & & \multirow{2}{*}{$69.6 \mathrm{~ns}$} & $2^{\text {nd }}$ spike: $59.6 \mathrm{~ns}$ \\
\cline { 3 - 4 } & & & $3^{\text {rd }}$ spike: $39 \mathrm{~ns}($ at $\mathrm{P}=1.2$ Torr $)$ \\
\hline
\end{tabular}




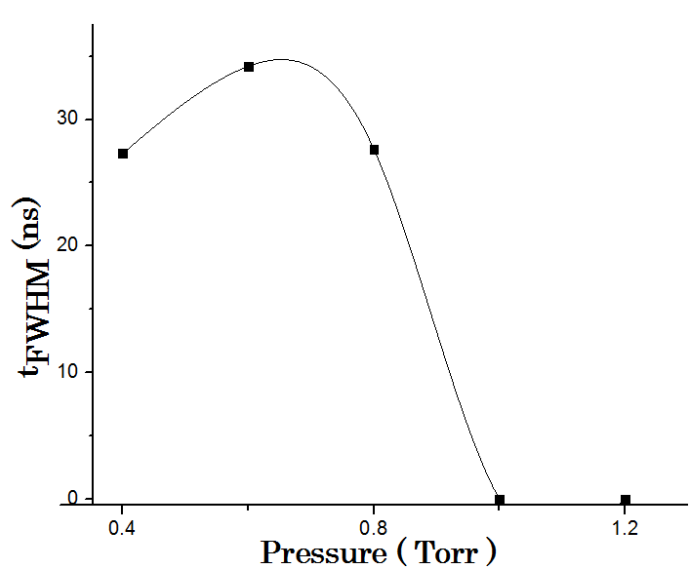

(a) $8 \mathrm{kV}$

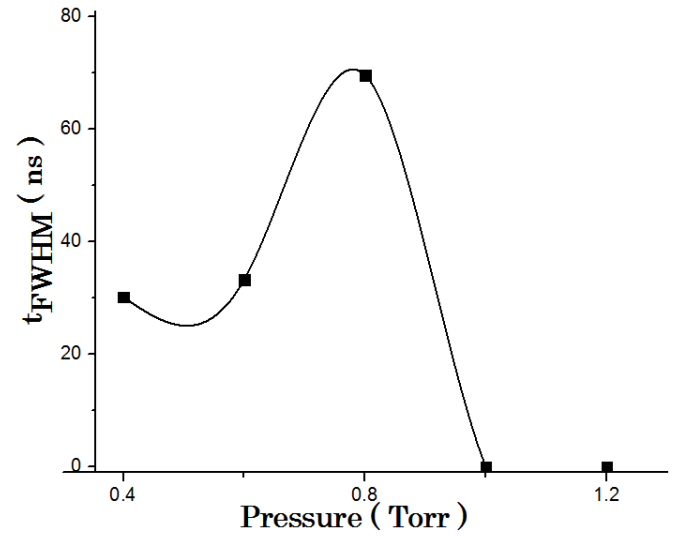

(b) $10 \mathrm{kV}$

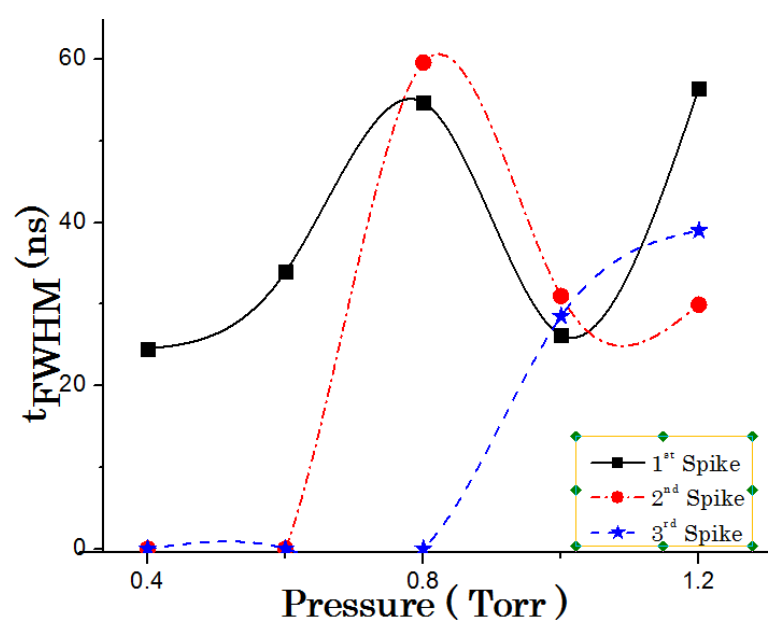

(c) $12 \mathrm{kV}$

Figure 4: FWHM time vs. gas pressure at (a) 8, (b) 10, and (c) $12 \mathrm{kV}$

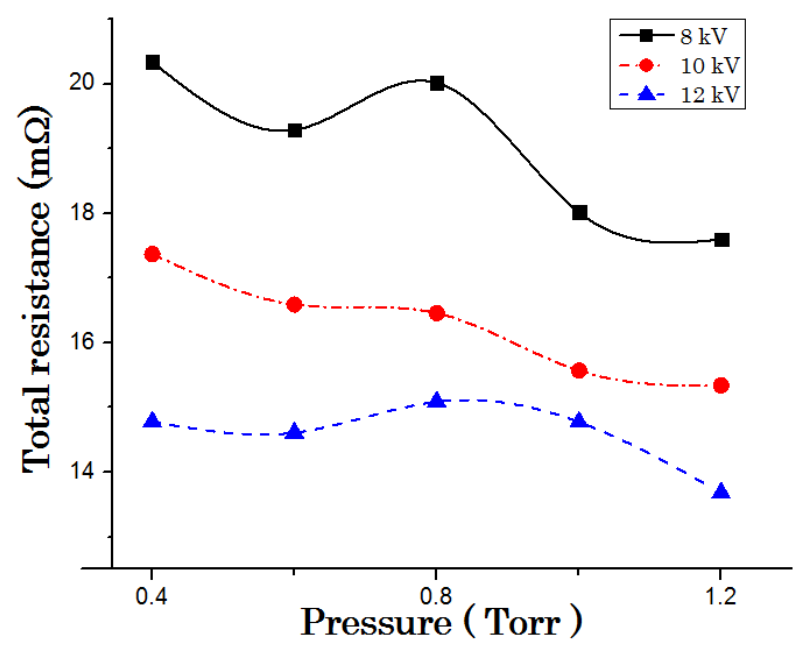

Figure 5: Total resistance vs. gas pressure

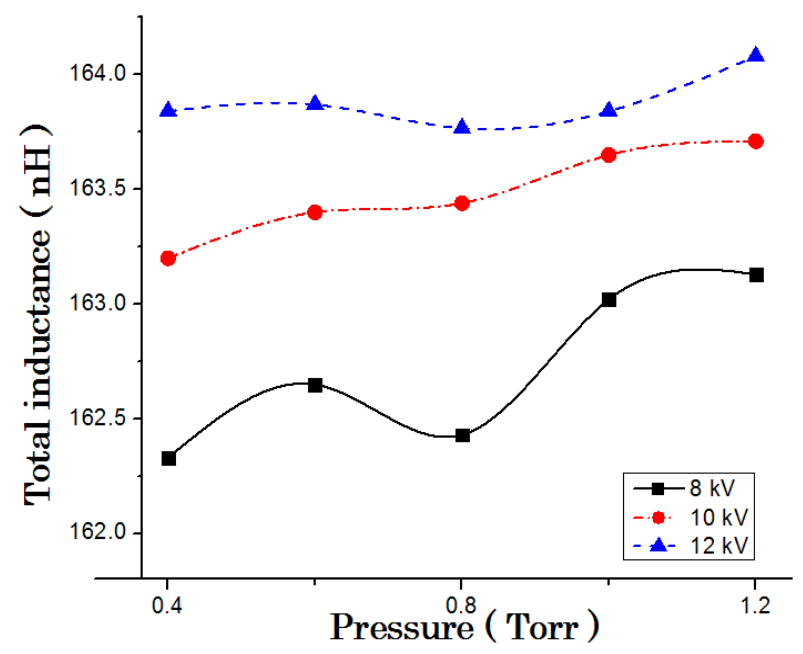

Figure 6: Total inductance vs. gas pressure

Table 2: Values of $R_{t}$ and $L_{t}$ at discharge conditions of optimum PF formation

\begin{tabular}{|c|c|c|c|}
\hline & $8 \mathrm{kV}-0.6$ Torr & $10 \mathrm{kV}-0.8$ Torr & $12 \mathrm{kV}-0.8$ Torr \\
\hline $\mathrm{R}_{\mathrm{t}}(\mathrm{m} \Omega)$ & 19.29 & 16.46 & 15.09 \\
\hline $\mathrm{L}_{\mathrm{t}}(\mathrm{nH})$ & 162.65 & 163.44 & 163.77 \\
\hline
\end{tabular}


The load impedance $(V / I)$ is the ratio between the discharge voltage and discharge current. It is shown in figure 7 as a function of time for different discharge conditions, wherein an optimum PF formation is investigated. This figure shows that the time distribution of load impedance is divided into three parts. The first part is $R_{\text {load }} \cong$ $56 \rightarrow 20 \mathrm{~m} \Omega$ (breakdown phase) with a time duration $\cong 1 \mu \mathrm{s}(0.5$ to $1.5 \mu \mathrm{s})$. The second part of $\mathrm{R}_{\text {load }}$ has a minimum value of average $\cong 10 \mathrm{~m} \Omega$ (this part represents an axial phase) with time duration of 1.5 to $3.75 \mu$ s for $12 \mathrm{kV}-0.8$ Torr conditions and 1.5 to $4 \mu$ s for both $8 \mathrm{kV}-0.6$ Torr and $10 \mathrm{kV}-0.8$ Torr conditions. At the time of maximum discharge current, $\mathrm{R}_{\text {load }}$ has a minimum value, which suggests a high conductive plasma current layer. The third part (during the beginning of collapse until the voltage spike) has a time duration of 3.75 to $4.24 \mu$ s for $12 \mathrm{kV}-0.8$ Torr conditions, 4 to $4.66 \mu \mathrm{s}$ for $10 \mathrm{kV}-0.8$ Torr conditions and 4 to $4.5 \mu \mathrm{s}$ for $8 \mathrm{kV}-0.6$ Torr conditions. The $R_{\text {load }}$ rises rapidly in this third part, reaching 60-100 $\mathrm{m} \Omega$ for the three discharge conditions under consideration. The $R_{\text {load }}$ increase may be due to a rapid change in focus geometry or to an anomalous plasma resistance caused by plasma turbulence. In general, we noticed that the maximum value of $R_{\text {load }}$ was detected at $V_{c h}=12$ $\mathrm{kV}$ and $P=0.8$ Torr.

The PCS inductance $\left(L_{p}\right)$ as a function of discharge time $(t)$ during the axial phase is estimated with the following equation [32]:

$$
\mathrm{L}_{\mathrm{p}}=\frac{\int \mathrm{Vdt}}{I_{t}}
$$

Figure 8 illustrates the description of $L_{p}$ with respect to $t$ at the discharge conditions where the best PF action was detected for the different charging voltages. This figure clearly shows that $L_{p}$ at the beginning of time collapse has a higher value at $12 \mathrm{kV}-0.8$ Torr than at the other two discharge conditions under consideration. Additionally, it is noticed that the charging voltage has no significant on $L_{p}$.

\section{Plasma implosion velocity}

The plasma implosion velocity $\left(V_{Z}\right)$ is the PCS velocity in the z-direction towards the muzzle. It is investigated as a function of time and axial distance $(Z)$ along the coaxial electrodes with the following equation [32]:

$$
L_{p}(t)=\frac{\mu 0}{2 \pi}\left(\ln \frac{b}{a}\right) Z(t)
$$

where $\mu_{0}$ is the magnetic permeability $=4 \pi \times 10^{-7}$ $H / m$ and ' $a$ ' and ' $b$ ' are the radii of the inner and outer electrodes, respectively. From the data in figure 8 , the variations in $Z$ and $t$ can be investigated for the different discharge conditions mentioned above, as shown in figure 9. From the variation in $d Z / d t=V_{Z}$ with respect to $t$ and $Z$, the plasma implosion velocity $\left(V_{Z}\right)$ as a function of $t$ and $Z$ is investigated, and the results are shown in figures 10,11 and 12 .

Figures 10, 11 and 12 illustrate that, for all discharge conditions, $V_{z}$ increased as time increased until reaching a maximum value at approximately the maximum discharge current ( $I_{\max }$ time $\left.\cong 3.5 \mu \mathrm{s}\right)$, and afterwards, $V_{z}$ decreased gradually as time increased despite increases in the discharge current (I). This phenomenon may be attributed to the current shedding effect, i.e., the CS carries a lower current value than the actual current. This effect gives rise to a lower CS velocity [33]. As the axial distance approaches the coaxial electrodes muzzle $(8 \mathrm{~cm}$ to $10 \mathrm{~cm})$, the CS velocity $\left(V_{z}\right)$ has a higher value when $V_{c h}=12 \mathrm{kV}$ and $P=0.8$ Torr than under the two other discharge conditions $(8 \mathrm{kV}-0.6$ Torr and $10 \mathrm{kV}-$ 0.8 Torr).

The current factor $\left(f_{c}\right)$ is a fraction of the discharge current swept by the PCS. The mass factor $\left(f_{m}\right)$ is the fraction of mass swept by the sheath motion. Note that $f_{c}$ and $f_{m}$ are estimated from the Lee model code (RADPFV5.15de.c1) [34], and consequently, the modification factor $\frac{f c}{\sqrt{f m}}[35]$ at the three discharge conditions in our study is as follows:

$\begin{array}{ll}\frac{f_{c}}{\sqrt{f_{m}}}=2.98 & V_{c h}=12 \mathrm{kV} \text { and } P=0.8 \text { Torr } \\ \frac{f_{c}}{\sqrt{f_{m}}}=3.367 & V_{c h}=10 \mathrm{kV} \text { and } P=0.8 \text { Torr } \\ \frac{f_{c}}{\sqrt{f_{m}}}=4.03 & V_{c h}=8 \mathrm{kV} \text { and } P=0.6 \text { Torr }\end{array}$

The above results indicated that the discharge condition with $V_{c h}=12 \mathrm{kV}$ and $P=0.8$ Torr has a less inefficient snowplow action than the other two conditions. 


\section{Energy dissipation}

The energy dissipation during the axial phase of PF discharge is investigated under the same three discharge conditions mentioned above. The energy is dissipated via four processes:

1) Magnetic energy storage $\quad E_{l}=1 / 2\left(L_{e}+f_{c}\right.$

2) Mechanical energy $\quad E_{2}=1 / 2 \int \frac{d L_{p}}{d t} I^{2} f_{c} d t$

3) External circuit ohmic losses $\quad E_{3}=I^{2} R_{e} t$

4) Plasma ohmic losses $\quad E_{4}=I^{2} f_{c}^{2} R_{p} t$

where $_{\mathrm{Lp}}$ is the plasma inductance, $R_{p}$ is the plasma resistance, $t$ is the time and $\mathrm{I}$ is the instantaneous discharge current.

The variation in the energy dissipation processes versus time is shown in figure 13 ( $a, b, c$ and $d$ ).

These figures verified that each energy dissipation section under consideration increased with increasing time.

Additionally, each energy dissipation section increased with increasing charging voltage from 8

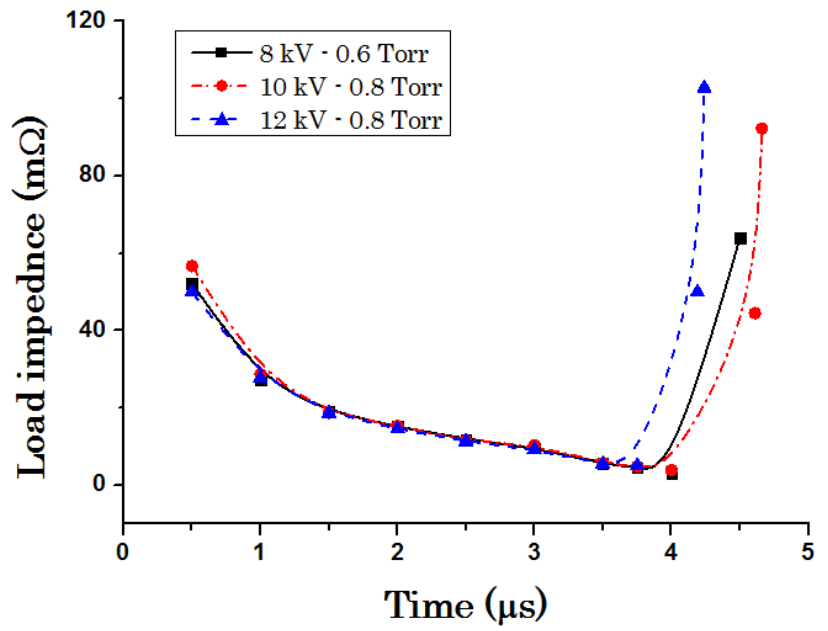

Figure 7: Load impedance vs. time to $12 \mathrm{kV}$. The total energy dissipation $\left(E_{t}\right.$, which is the sum of the four items a, b, c and d) is represented in figure 14 as a function of time. This distribution has the same profile as figure $13(a, b$, $\mathrm{c}$ and d), and the maximum value of $E_{t}$ is detected at $V_{c h}=12 \mathrm{kV}$ and $P=0.8$ Torr; $\mathrm{E}_{\mathrm{t}}$ increases from 0.631 to $1.984 \mathrm{~kJ}$ under these conditions. The ratio between $E_{t}$ and the input energy $\left(E_{\text {input }}=1 / 2 C_{0} V_{c h}{ }^{2}\right)$ $\left(E_{/} / E_{\text {input }}\right)$ as a function of time, is shown in figure 15 for the three different discharge conditions. From this relation, we can see that $E / E_{\text {input }}$ at the end of the axial phase and immediately before the collapse stage has a maximum value at $V_{c h}=12 \mathrm{kV}$ and $P=0.8$ Torr, where $E_{l} / E_{\text {input }}$ increases from $29.24 \%$ to $91.88 \%$ during the axial phase time.

The difference between $E_{\text {input }}$ and $E_{t}$ represents the unused electrical energy. This value is proportional to the charge left on the capacitor bank.

A comparison between the maximum values of total energy and the unused energy is shown in figure 16 as a function of charging voltage. The ratio of maximum unused energy to total energy dissipation is shown in figure 17. This ratio decreased from $14.58 \%$ to $8.84 \%$ as the charging voltage increased from 8 to $12 \mathrm{kV}$.

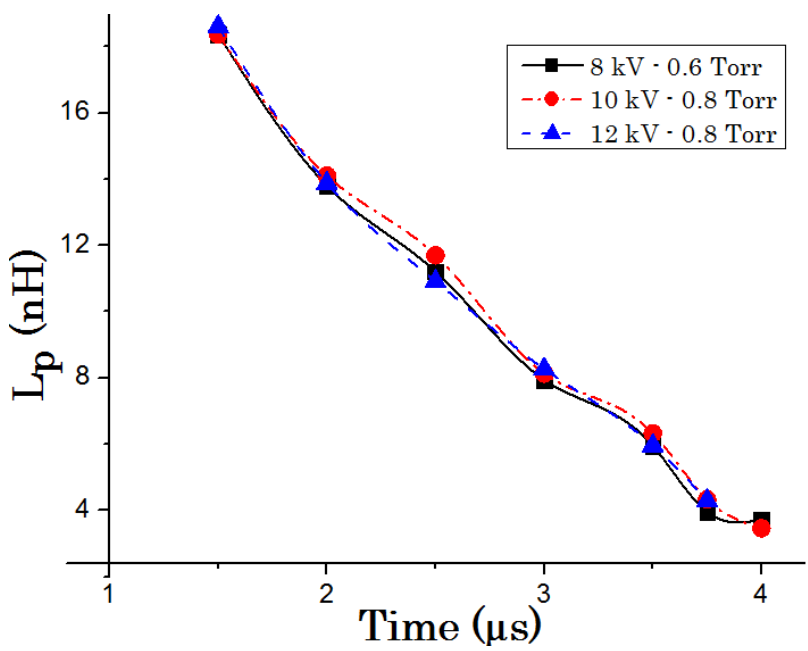

Figure 8: Plasma inductance (Lp) vs. time 


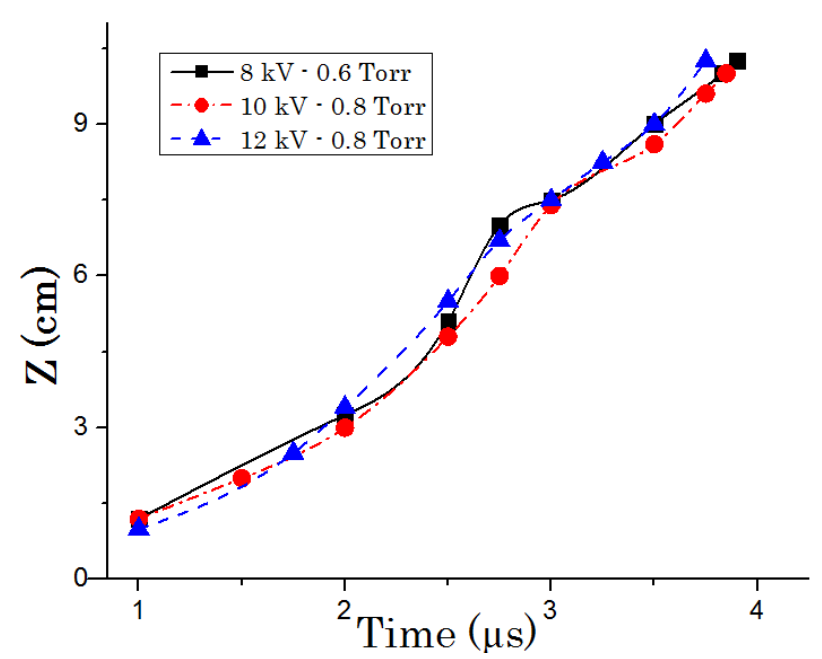

Figure 9: Variation in axial distance $(Z)$ with respect to time

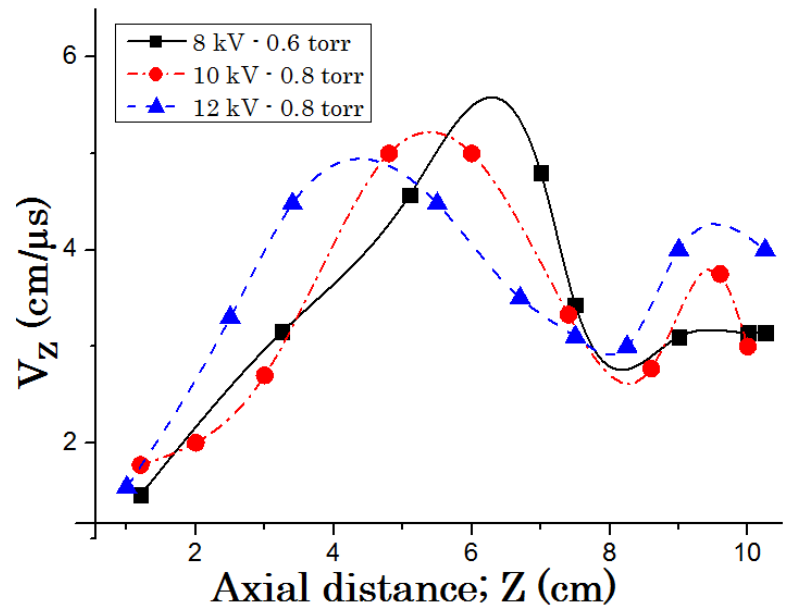

Figure 11: Variation in plasma implosion velocity with respect to axial distance.

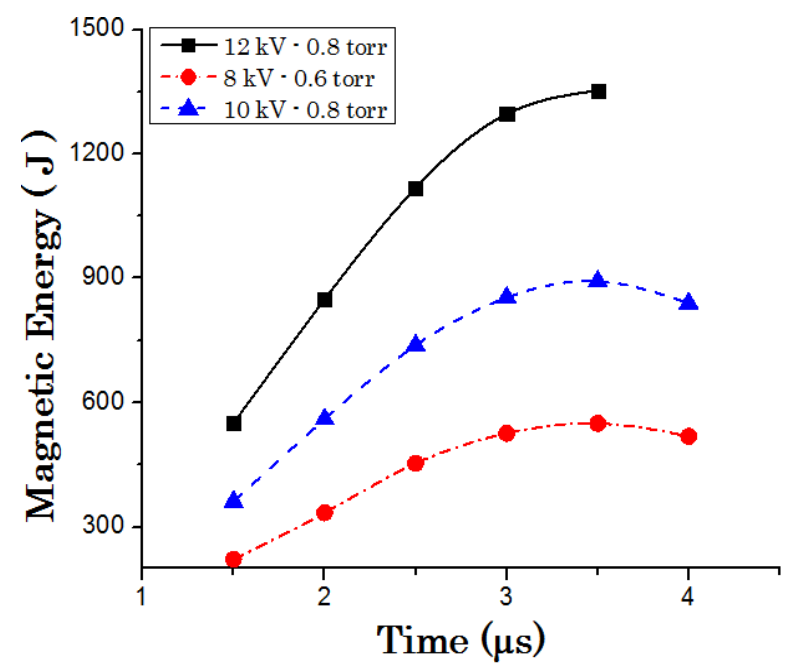

(a) Magnetic energy vs. time

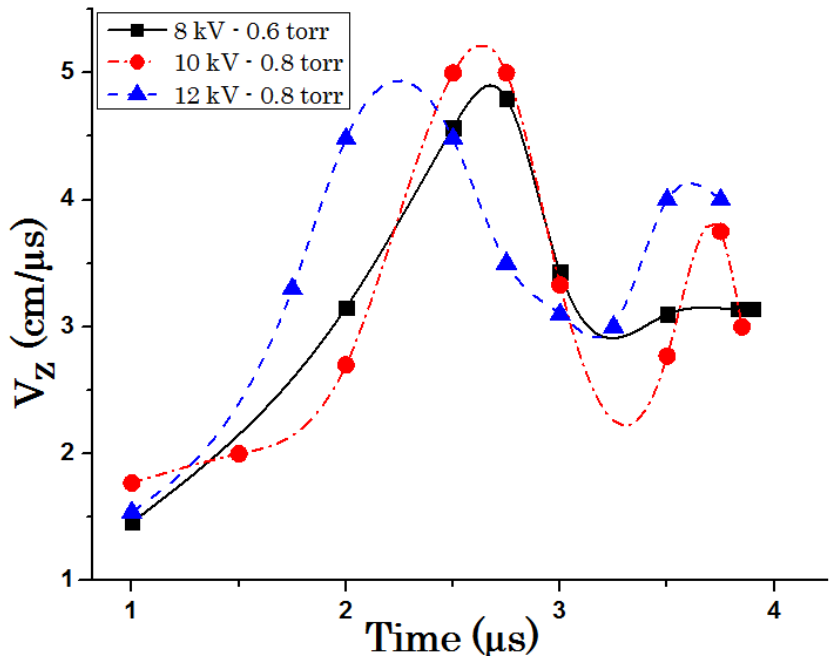

Figure 10: Variation in plasma implosion velocity with respect to time

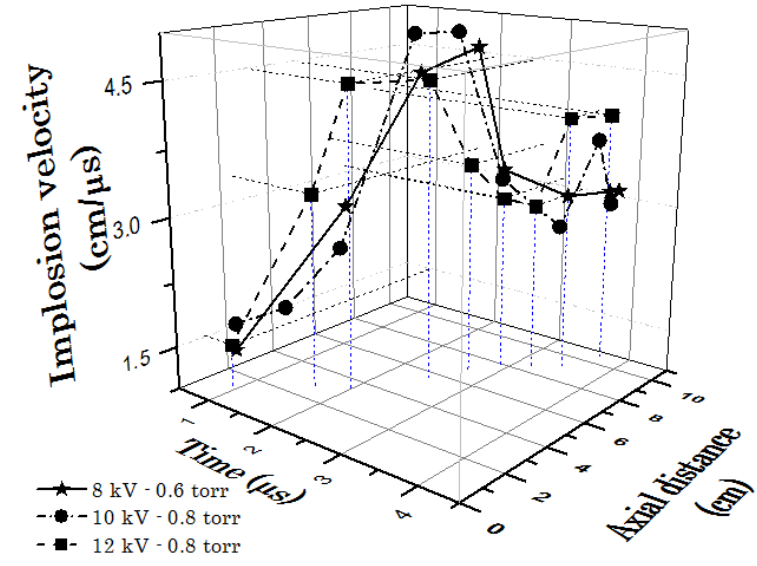

Figure 12: 3D relation of $\mathrm{VZ}, \mathrm{Z}$ and $\mathrm{t}$.

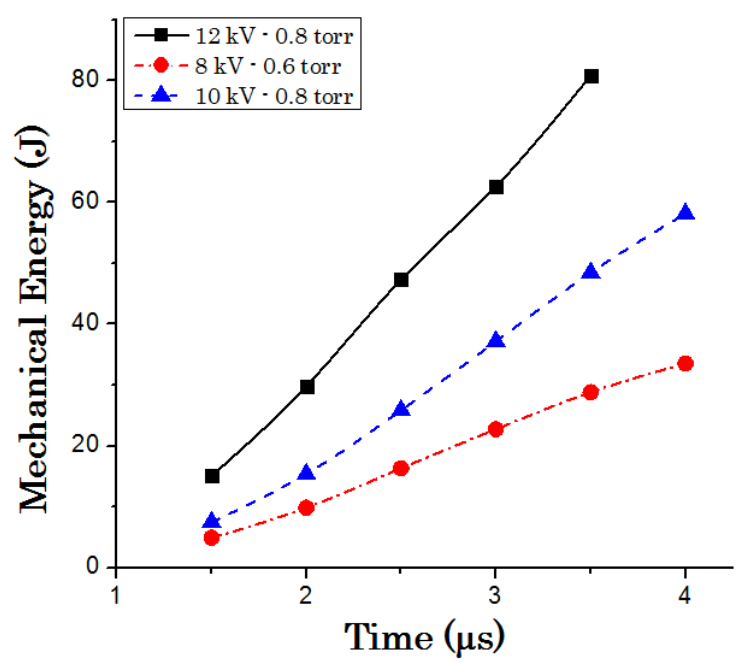

(b) Mechanical energy vs. time 


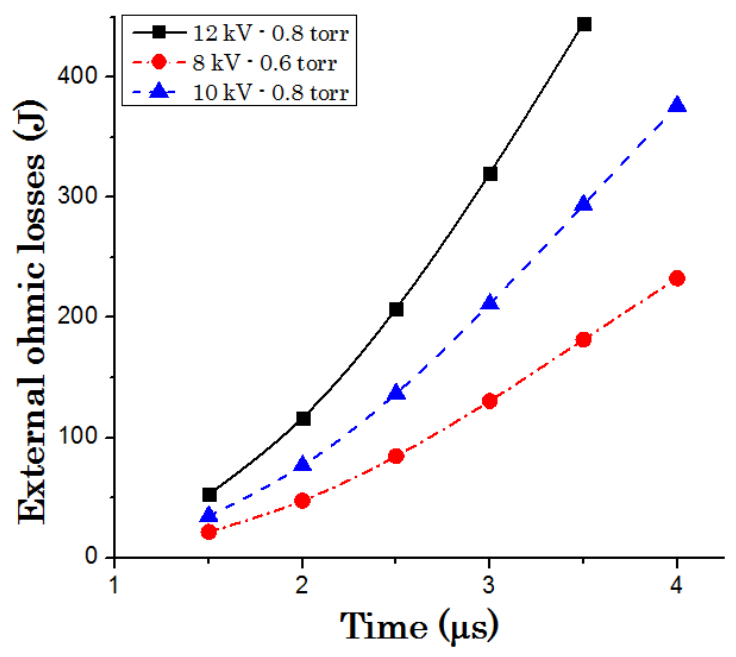

(c) External ohmic losses vs. time

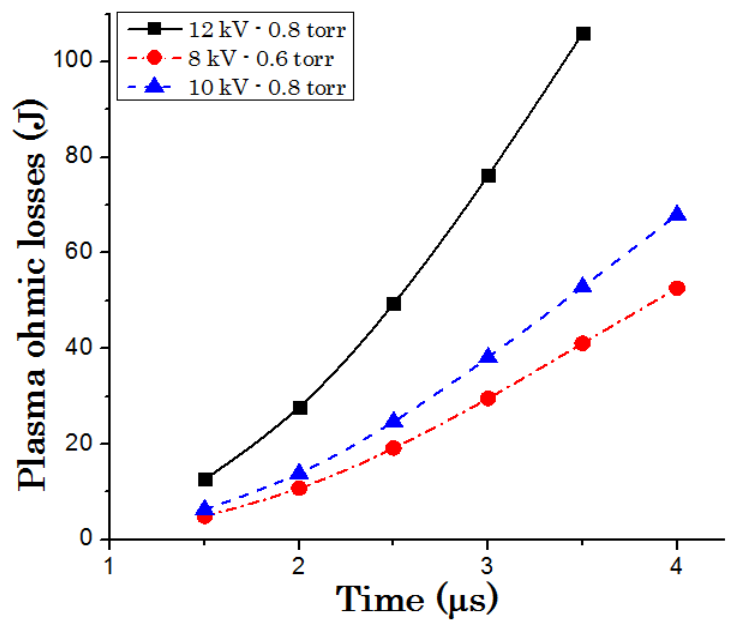

(d) Plasma ohmic losses vs. time

Figure 13: Energy dissipation processes vs. time

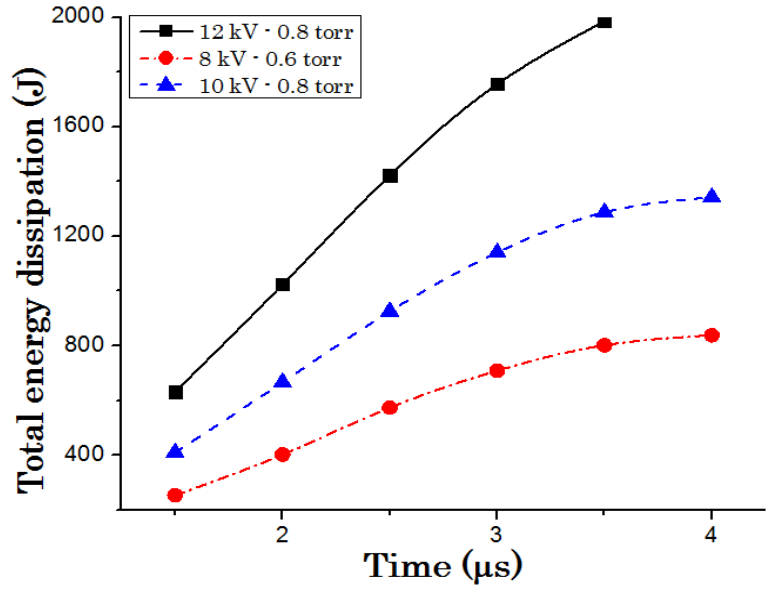

Figure 14: Total energy dissipation vs. time

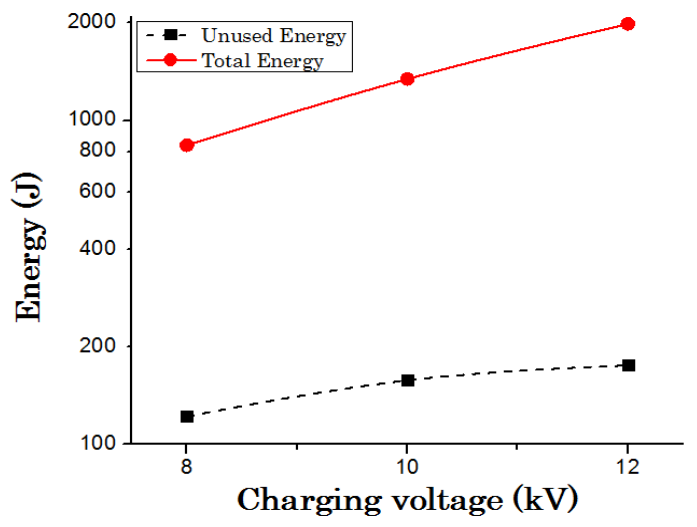

Figure 16: Maximum values of total energy and unused energy (shown in log scale) vs. charging voltage.

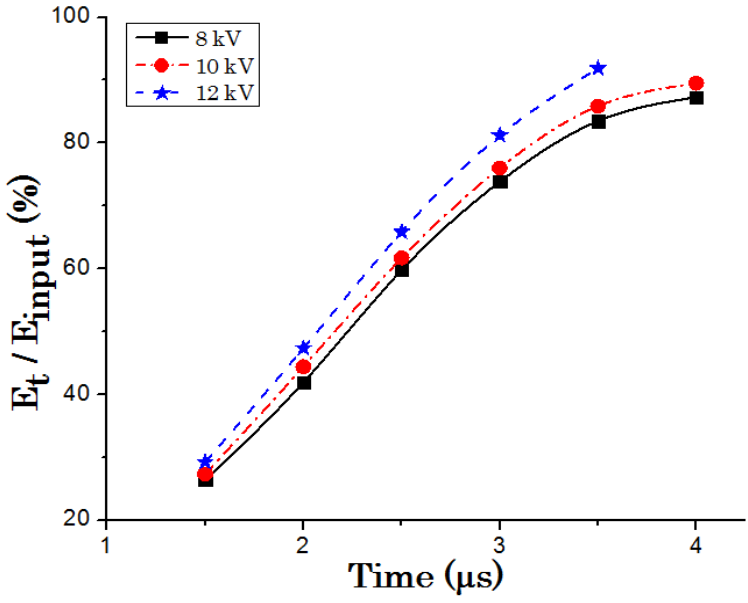

Figure 15: Et/Einput vs. time

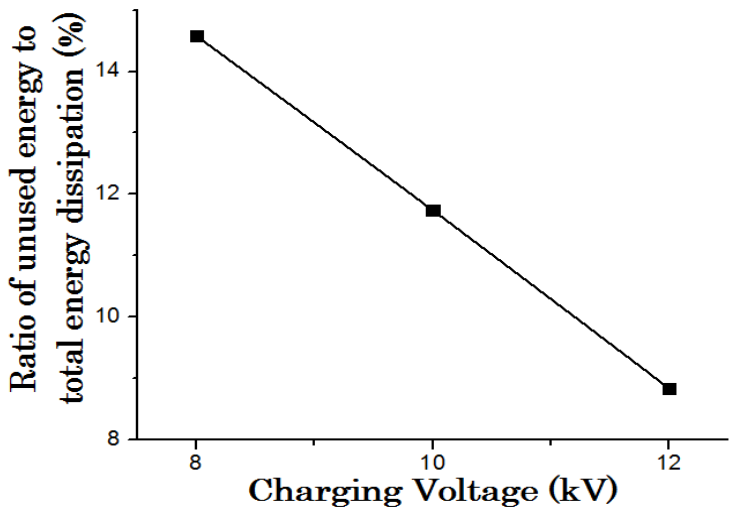

Figure 17: Ratio of unused energy to total energy dissipation vs. charging voltage. 


\section{Conclusion}

The PF device (EAEA - PF1) was operated at different charging voltages $(8-12 \mathrm{kV})$ and various argon gas pressures ranging from 0.4-1.2 Torr. The experimental results of the PF action at each charging voltage and at different gas pressures demonstrated that the focus action is a very sensitive function of discharge conditions. The best focus action at $8 \mathrm{kV}, 10 \mathrm{kV}$, and $12 \mathrm{kV}$ was detected at 0.6 Torr, 0.8 Torr, and 0.8 Torr, respectively. The best optimized PF action was obtained at $12 \mathrm{kV}$ and 0.8 Torr; under these conditions, the electrical parameters, particularly the load impedance and plasma inductance, each had a higher value at the beginning of the radial phase than under any other two discharge conditions. The PCS dynamics results at the different discharge conditions of best PF formation mentioned above clearly showed that the implosion plasma velocity at the coaxial electrodes muzzle (i.e., before the beginning of the radial phase) had a maximum value at $\mathrm{V}_{\mathrm{ch}}=12 \mathrm{kV}$ and $\mathrm{P}$ $=0.8$ Torr. Furthermore, a less inefficient snowplow action was detected under these conditions. The energy dissipation data during the $\mathrm{PF}$ discharge processes as a function of the argon gas pressure and at different charging voltages where the best PF formed clearly demonstrated two findings. First, the ratio between total energy dissipation and the input energy had a higher value at $\mathrm{V}_{\mathrm{ch}}=12 \mathrm{kV}$ and $\mathrm{P}=0.8$ Torr than under the other two discharge conditions $\left(\mathrm{V}_{\mathrm{ch}}=10 \mathrm{kV}\right.$ and $\mathrm{P}$ $=0.8$ Torr and $\mathrm{V}_{\mathrm{ch}}=8 \mathrm{kV}$ and $\mathrm{P}=0.6$ Torr). Second, the ratio of the maximum value of residual or unused energy in the condenser bank to the total energy dissipation decreased with increasing charging voltage $(8-12 \mathrm{kV})$, reaching a minimum value at $\mathrm{V}_{\text {ch }}=12 \mathrm{kV}$ and $\mathrm{P}=0.8$ Torr.

Hence, it can be concluded that the PCS dynamics during the axial phase, the electrical parameters of the plasma and the amount of energy dissipation during the PF discharge depend on the PF formation discharge conditions.

\section{References}

1. N. V. Filippov, T. I. Filippova, and V. P. Vinogradov (1962) Dense high-temperature plasma in a non-cylindrical Z-pinch compression, Nuclear Fusion Supplement, Pt.2: 577.
2. J. W. Mather (1963) Investigation of the High-Energy Acceleration Mode in the Coaxial Gun, Physics of Fluids,7: S28.

3. J. W. Mather and P. J. Bottoms (1968) Characteristics of the dense plasma focus discharge," The Physics of Fluids, 11(3): 611618.

4. J. Marshall, (1954) Acceleration of plasma into vacuum," Journal of Nuclear Energy, 7(34): 276.

5. S. Lee, T. Y. Tou, S. P. Moo, M. A. Eissa, A. V. Gholap, K. H. Kwek, S. Mulyodrono, A. J. Smith, S. W. Usada, and M. Zakaullah (1988) A simple facility for the teaching of plasma dynamics and plasma nuclear fusion, American Journal of Physics, 56(1): 62-68.

6. M. Zakaullah, K. Alamgir, M. Shafiq, S. M. Hassan, M. Sharif, S. Hussain, and A. Waheed (2002) Characteristics of X-rays from a plasma focus operated with neon gas, Plasma Sources Science and Technology, 11(4): 377-382.

7. A. Szydlowski, M. Scholz, L. Karpinski, M. Sadowski, K. Tomaszewski, and M. Paduch (2001) Neutron and fast ion emission from PF1000 facility equipped with new large electrodes, NUKLEONIKA, 46: S61-S64.

8. S. H. Saw, S. Lee, F. Roy, P. L. Chong, V. Vengadeswaran, A. S. M. Sidik, Y. W. Leong, and A. Singh (2010) In situ determination of the static inductance and resistance of a plasma focus capacitor bank, Review of Scientific Instruments, 81: 053505.

9. A. Bernard et al. (1998) Scientific status of plasma focus research, Moscow J Phys Soc, 8(2): 93-170.

10. F. S. Karimi, S. Saviz, M. Ghoranneviss, M. K. Salem, and F. M. Aghamir (2017) The circuit parameters measurement of the SABALAN-I plasma focus facility and comparison with Lee Model, Results in Physics, 7: 1859-1869.

11. [11] F. Veloso, C. Pavez, J. Moreno, V. Galaz, M. Zambra, and L. Soto (2012) Correlations Among Neutron Yield and Dynamical Discharge Characteristics Obtained from Electrical Signals in a $400 \mathrm{~J}$ Plasma Focus, Journal of Fusion Energy, 31: 30-37.

12. [M. O. Barbaglia, M. Milanese, L. Soto, A. Clausse, J. Moreno, C. Pavez, and C. Moreno (2016) Temporal Variation of the Current

Arab J. Nucl. Sci. \& Applic. Vol. 53, No. 1 (2020) 
Sheet Inductance from PACO Plasma Focus Device, Journal of Fusion Energy, 35(3): 561566.

13. H. Bruzzone, H. N. Acuña, M. O. Barbaglia, M. M. Milanese, R. Miklaszewski, M. Paduch, E. Zieliñska, and A. Clausse, (2016) TimeVarying Inductance of the Plasma Sheet in the PF1000 Plasma-Focus Device, IEEE Transactions on Plasma Science, 44(6): 1-5.

14. B. L. Bures, M. Krishnan, and R. E. Madden (2011) Relationship Between Neutron Yield and Macroscale Pinch Dynamics of a $1.4-\mathrm{kJ}$ Plasma Focus Over Hundreds of Pulses, IEEE Transactions on Plasma Science, 39(12): 3351-3357.

15. F. Veloso, L. Soto, C. Pavez, and J. Moreno (2014) Initial stages in hundreds of Joules plasma focus operating in deuterium - argon mixtures: Preliminary results, Journal of Physics Conference Series, 511(1): 012027.

16. T. M. Allam, G. M. El-Kashef, and T. F. Emara (2013) Study of the Correlation between the Plasma Sheath Dynamical Behavior and the Best Focus Action, Arab Journal of Nuclear Science and Applications, 46(1): 163-171.

17. H. A. El-Sayed, T. M. Allam, and H. M. Soliman, Effect of Inner Electrode Length of $2.2 \mathrm{~kJ}$ Mather Type Plasma Focus on Focus Action, Journal of Advances in Physics, 10(3): 2802-2810.

18. M. Mathuthu, T. G. Zengeni, and A. V. Gholap (1998) Variation of focus action with electrode length for an inner electrode of negative polarity, IEEE Transactions on Plasma Science, 26(1): 14 - 18.

19. M. Zakaullah, T. J. Baig, S. Beg, and G. Murtaza (1989) Effect of insulator sleeve length on neutron emission in a plasma focus, Physics Letters A, 137(1-2): 39-43.

20. F. N. Beg, M. Zakaullah, and G. Murtaza (1992) Effect of insulator sleeve material on neutron emission from a plasma focus, Physica Scripta, 46(2): 152-154.

21. G. R. Decker, W. Kies, and G. Pross (1982) Experiments solving the polarity riddle of the plasma focus, Physics Letters A, 89(8): 393396.

22. M. Mathuthu, T. G. Zengeni, and A. V. Gholap (1997) Design, fabrication, and characterization of a $2.3 \mathrm{~kJ}$ plasma focus of negative inner electrode, Review of Scientific Instruments, 68(3): 1429-1432.

23. B. Shirani and F. Abbasi (2010) Construction and Experimental Study of a $2.5 \mathrm{~kJ}$, Simply Configured, Mather Type Plasma focus device, Brazilian Journal of Physics, 40(2): 125-130.

24. B. Shan (2000), "Comparative Study of Dynamics and X-Ray Emission of Several Plasma Focus Device," Nanyang Technological University, $\mathrm{PhD}$ Thesis.

25. M. A. Mohammadi, S. Sobhanian, M. Ghomeishi, E. Ghareshabani, M. Moslehifard, S. Lee, and R. S. Rawat (2009) Current Sheath Dynamics and its Evolution Studies in Sahand Filippov Type Plasma Focus, Journal of Fusion Energy, 28: 371-376.

26. R. I. Mahmud (2014) "Theoretical study to design plasma focus machine and investigate various parameters that affect its emitted neutron yield," Council of College of Education - Ibn Al-Haitham University of Baghdad, Baghdad - Republic of Iraq, M.Sc. Thesis - chapter 2.

27. M. Frignani (2007) "Simulation of Gas Breakdown and Plasma Dynamics in Plasma Focus Devices," University of Bologna, Bologna - Italy, PhD thesis - chapter 1.

28. M. S. Rafique, (2000) "Compression Dynamics and Radiation Emission from a Deuterium Plasma Focus," National Institute of Education-Nanyang Technological University, Singapore, PhD thesis-Chapter 4.

29. D. Ngamrungroj, R. Mongkolnavin, and C. S. Wong (2005) Efficiency of Energy Transfer in a Small Plasma Focus Device, Solid State Phenomena, 7: 95-98.

30. H. A. El-Sayed, T. M. Allam, and H. M. Soliman (2019) Plasma current sheath shape and trapping efficiency in $2.2 \mathrm{~kJ}$ (EAEA-PF1) plasma focus device, Plasma physics reports, 45(9): 821-829.

31. A. F. Kip (1969), "Fundamental of electricity and magnetism," McGraw-Hill ( $2^{\text {nd }}$ edition).

32. S. Lee (2014) Plasma focus radiative model: review of the Lee model code, J Fusion Energ. 33: 319.

33. S. P. Chow, S. Lee, and B. C. Tan (1972) Current sheath studies in a co-axial plasma 
focus gun, Journal of Plasma Physics, 8(1): 21-31.

34. http://www.plasmafocus.net/.

35. H. R. Yousefi, G. R. Etaati, and M. Ghorannevis (2004) Insulator length effects in
Mather-Type Plasma Focus Device, in $31^{\text {st }}$ European Physical Society Conference on Plasma Physics, London, UK, pp. P-5.006. 